\title{
Optimization Study of the Removal of Atrazine from Aqueous Solution on to Composite Activated Carbon-Silver Using Response Surface Methodology
}

\author{
Nkwaju Yanou Rachel1,2, Baçaoui Abdelaziz², Kouotou Daouda1, Ndi Nsami Julius1*, \\ Dammi Djimi Estelle Gaelle1, Yaacoubi Abdelrani'2, Louarrat Mehdi², Ketcha Mbadcam Joseph ${ }^{1}$ \\ ${ }^{1}$ Applied Physical and Analytical Chemistry Laboratory, Department of Inorganic Chemistry, Faculty of Science, University of \\ Yaoundé I, Yaoundé, Cameroon \\ ${ }^{2}$ Applied Organic Chemistry Laboratory, Department of Chemistry, Faculty of Science Semlalia Marrakech, University Cadi \\ Ayyad, Marrakech, Morocco \\ Email: `bigpielo2002@yahoo.com
}

How to cite this paper: Rachel, N.Y., Abdelaziz, B., Daouda, K., Julius, N.N., Gaelle, D.D.E., Abdelrani, Y., Mehdi, L. and Joseph, K.M. (2017) Optimization Study of the Removal of Atrazine from Aqueous Solution on to Composite Activated Carbon-Silver Using Response Surface Methodology. Materials Sciences and Applications, 8, 258-272.

https://doi.org/10.4236/msa.2017.83018

Received: December 23, 2016

Accepted: March 24, 2017

Published: March 27, 2017

Copyright ( 92017 by authors and Scientific Research Publishing Inc. This work is licensed under the Creative Commons Attribution International License (CC BY 4.0).

http://creativecommons.org/licenses/by/4.0/ (c) (i) Open Access

\begin{abstract}
Activated carbon based oil palm shells were prepared by physical activation using steam which was further grafted with silver. The Response Surface Methodology (Doehlert design) was used to optimize both the impregnation of silver and the atrazine removal. The effects of three variables of preparation conditions of the composite activated Carbon-Silver (AC-Ag): Concentration of silver, impregnation temperature and impregnation time on the atrazine removal $\left(\mathrm{Y}_{1}\right)$ was investigated on one hand. In another hand, three variables of atrazine removal from liquid phase: Temperature, $\mathrm{pH}$ and ratio of Atrazine/ $\mathrm{CaCl}_{2}\left(\mathrm{r}\left(\mathrm{Atraz} / \mathrm{CaCl}_{2}\right)\right)$ on the adsorption capacity of atrazine $\left(\mathrm{Y}_{2}\right)$ were also investigated. Based on the Doehlert designs, the quadratic models were developed to correlate the preparation variables and the adsorption variables to the response. The optimum conditions of preparation of AC-Ag were found to be: Concentration of silver of $0.063 \mathrm{~mol} / \mathrm{L}$, impregnation temperature of $223^{\circ} \mathrm{C}$, impregnation time of 1.3 hand atrazine removal of 384.62 $\mathrm{mg} / \mathrm{g}$. The optimum conditions of atrazine adsorption were found to be: Temperature of $25.0^{\circ} \mathrm{C}, \mathrm{pH}$ of 7.7 and $\mathrm{r}\left(\mathrm{Atraz} / \mathrm{CaCl}_{2}\right)$ of 0.37 which gave 209 $\mathrm{mg} / \mathrm{g}$ of atrazine adsorption capacity. These results demonstrated that the preparation and adsorption conditions have a significant influence on the removal of atrazine.
\end{abstract}

\section{Keywords}

Adsorption, Atrazine Herbicide, Optimization, Activated Carbon/Silver, Response Surface Methodology 


\section{Introduction}

Atrazine (2-chloro-4-ethylamine-6 isopropylamino-s-triazine) is a selective triazine herbicide frequently used in agricultural sector. Contamination of water and soil by atrazine has a negative impact on aquatic ecosystems and induce severe hormonal disturbances in amphibians [1]. Thus it is classified as a potential human carcinogenic by USEPA (United States Environmental Protection Agency) and the main source of human exposure is the consumption of contaminated groundwater [2]. Therefore, the European Union legislation allows a very low concentration of atrazine in drinking water $(0.1 \mathrm{ppb})$ and USEPA has also set a maximum contaminant level at $3 \mathrm{ppb}$ for it [3]. It becomes important to clean atrazine from groundwater.

One effective alternative to eliminate this recalcitrant compound could be the adsorption process. Adsorption is a process whereby a contaminant adheres to the surface of an adsorbent, such as activated carbon, due to hydrophobic and electrostatic interactions between the adsorbate and the adsorbent [4]. Activated carbon (AC) is a carbonaceous material that possesses a highly developed porosity that allows its use in wide range of applications. Some of the most important uses dealt with water treatment [5].

Activated carbons are widely used to adsorb organic micropollutant from liquids or gas [6]. They can be obtained from various precursors such as oil palm shell, argan shell, coconut shell, peat, sugar canne bagasse. Sorption studies of atrazine have mainly been limited to activated carbon. But the presence of active silver metal onto impregnated activated carbon surface can greatly affect the adsorption affinity since inorganic compounds with the multiplication of the application and properties. Some other factors such as $\mathrm{pH}$, temperature and ionic strength $\mathrm{pH}$ could have a significant effect in the adsorption of atrazine. For this reason, the Response Surface Methodology was used to optimize the impregnation of silver on the surface of the activated carbon for atrazine adsorption (response). The activated carbon thus obtained will be used for atrazine removal from liquid phase. Doehlert designs are easily applied to optimize variables and was selected to study firstly the effects of activated carbon preparation/silver variables (concentration of $\mathrm{AgNO}_{3}$, temperature and time of impregnation); secondly the effects of atrazine removal variable ( $\mathrm{pH}$, temperature and ionic strength) on the response. Thus; the objective of this work was to optimize the preparation of composite activated carbon/silver for the removal of atrazine.

\section{Materials and Methods}

\subsection{Preparation of the Composite}

The Oil palm shells were collected locality from Bafangin the West region of Cameroon. The precursor was cleaned several times with ionized water and sun dried. Then, they were crushed and sieved to particle sizes ranging from $2.0-2.5$ $\mathrm{mm}$. The dried residues were carbonized in a furnace tube (Carbolite1200C UK) 
at $400^{\circ} \mathrm{C}$ for $2 \mathrm{~h}$ under a flow of $\mathrm{N}_{2}$ gas, at a heating rate of $10^{\circ} \mathrm{C} / \mathrm{min}$. Before, it was activated at $850^{\circ} \mathrm{C}$ for $6 \mathrm{~h}$ (heating rate of $\left.10^{\circ} \mathrm{C} / \mathrm{min}\right)$ under steam $(0.1$ $\mathrm{mL} / \mathrm{min}$ ) and cooled to room temperature. After activation, the samples were washed in distilled water, dried, ground, and sift to obtain powder with particle size less than $50 \mu \mathrm{m}$. To functionalize the surface of activated carbon, the activated carbons were treated with $\mathrm{HNO}_{3}(1 \mathrm{~mol} / \mathrm{L})$.

Activated carbon-silver composites were prepared from the suspension of $0.6 \mathrm{~g}$ of activated carbon in $1.6 \mathrm{~mL}$ of water at desired concentration (0.05 - 0.1 $\mathrm{mol} / \mathrm{L}$ ) of silver $\left(\mathrm{AgNO}_{3}\right)$. The mixture was introduced in the furnace tube (at hydrothermal carbonization) in the dark. After $1 \mathrm{~h}$, the temperature was increased in the range $\left(188^{\circ} \mathrm{C}-292^{\circ} \mathrm{C}\right)$ at the desire time in the domain of $(1.3$ $3.7 \mathrm{~h})$. Then, the composite was washed with distilled water and dried at $105^{\circ} \mathrm{C}$ until constant weight and kept in a hermetic bottle for further test.

\subsection{Characterization of the Composite}

The composites were characterized using powder EDX for the chemical composition of the AC-AgFT-IR spectroscopy was applied in order to identify the functional groups and chemical bonding on the adsorbents. For this purpose, spectra were determined between 4000 and $400 \mathrm{~cm}^{-1}$ using an FT-IR spectroscope (Spectrum Vertex 70 DTGS). The morphological analysis of the activated carbon was performed by Scanning Electron Microscopy (SEM) (JEOL JSM-5400, Japan).

\subsection{Experimental Design}

Response Surface Methodology (RSM) is a collection of mathematical and statistical techniques that are useful for modeling and analysis of problems in which a response of interest is influenced by several variables [7]. In this work, The Doehlert experimental design was applied in order to reduce the number of experiments to study the variables of impregnation of activated carbon by silver in one hand and the variables for adsorption of atrazine from aqueous solution using the composite activated carbon-silver (AC-Ag) in a batch process in another hand. Doehlert matrices present the advantage of being easily expanded in both the variables space and the experimental space. This method was chosen for fitting a quadratic surface with a minimum number of experiments. It helps also to analyse the interaction between the effective process parameters and to identify the factor settings that optimize the response [8].

In the present study, the composite AC-Ag was prepared using hydrothermal carbonization by varying the preparation variables using Doehlert experimental design. The variables studies were: concentration of $\mathrm{AgNO}_{3}\left(\mathrm{X}_{1}\right)$; impregnation temperature $\left(\mathrm{X}_{2}\right)$ and impregnation time $\left(\mathrm{X}_{3}\right)$. For the adsorption of atrazine, three independent tests were chosen for the statistical experimental design as follows: temperature $\left({ }^{\circ} \mathrm{C}\right)\left(\mathrm{X}_{1}\right), \mathrm{pH}\left(\mathrm{X}_{2}\right)$ and ionic strength (atrazine/CaCl 2$)\left(\mathrm{X}_{3}\right)$. The range and levels of the factors which were varied according to the experimental design are given in Table 1 and Table 2. 
Table 1. Experimental design Matrix, operating conditions and the corresponding experimental response for impregnation activated carbon (AC-Ag).

\begin{tabular}{ccccc}
\hline Exp & $\begin{array}{r}{\left[\mathrm{AgNO}_{3}\right]} \\
(\mathrm{mol} / \mathrm{L})\end{array}$ & $\begin{array}{r}\text { Impregnation temperature } \\
\left({ }^{\circ} \mathrm{C}\right)\end{array}$ & $\begin{array}{c}\text { Impregnation times } \\
(\mathrm{h})\end{array}$ & $\mathrm{Y}_{1}(\mathrm{mg} / \mathrm{g})$ \\
\hline 1 & 0.100 & 240 & 2.5 & 344.83 \\
2 & 0.050 & 240 & 2.5 & 357.14 \\
3 & 0.087 & 292 & 2.5 & 294.12 \\
4 & 0.063 & 188 & 2.5 & 344.83 \\
5 & 0.087 & 188 & 2.5 & 333.33 \\
6 & 0.063 & 292 & 2.5 & 285.71 \\
7 & 0.087 & 257 & 3.7 & 277.80 \\
8 & 0.063 & 223 & 1.3 & 384.62 \\
9 & 0.087 & 223 & 1.3 & 333.30 \\
10 & 0.075 & 275 & 1.3 & 370.40 \\
11 & 0.063 & 257 & 3.7 & 270.00 \\
12 & 0.075 & 240 & 3.7 & 333.00 \\
13 & 0.075 & 240 & 2.5 & 294.11 \\
14 & 0.075 & 240 & 2.5 & 294.12 \\
15 & 0.075 & 240 & 2.5 & 297.00 \\
16 & 0.075 & 0.075 & 240.03 & \\
\hline 17 & 240 & & 2.5 \\
\hline
\end{tabular}

$\mathrm{Y}_{1}$ : Experimental response; Exp: experiment.

Table 2. Estimated values of coefficients for $Y_{1}$.

\begin{tabular}{ccccc}
\hline Name & Coefficient & Standard déviation & t.exp & Signif. \% \\
\hline $\mathrm{b}_{0}$ & 297.452 & 2.884 & 103.14 & $<0.01^{* * *}$ \\
$\mathrm{~b}_{1}$ & -8.904 & 3.224 & -2.76 & $2.74^{*}$ \\
$\mathrm{~b}_{2}$ & -28.168 & 3.224 & -8.74 & $<0.01^{\star * *}$ \\
$\mathrm{~b}_{3}$ & -42.360 & 3.224 & -13.14 & $<0.01^{\star * *}$ \\
$\mathrm{~b}_{11}$ & 53.533 & 5.395 & 9.92 & $<0.01^{\star * *}$ \\
$\mathrm{~b}_{22}$ & 4.883 & 5.396 & 0.91 & 39.9 \\
$\mathrm{~b}_{33}$ & 31.497 & 5.064 & 6.22 & $0.0550^{\star * *}$ \\
$\mathrm{~b}_{12}$ & 11.495 & 7.447 & 1.54 & 16.4 \\
$\mathrm{~b}_{13}$ & 32.139 & 8.325 & 3.86 & $0.633^{* *}$ \\
$\mathrm{~b}_{23}$ & -67.073 & 8.325 & -8.06 & $0.0141^{\star * *}$ \\
\hline
\end{tabular}

The experimental design matrix of 17 experiments and the results are given in Table 3. Each row represents an experimental run, and each column represents the variables tests. The response analyzed was the atrazine uptake. The responses are assuming to be affected by three variables and the experimental data were analyzed to fit the following second order polynomial equation: 


$$
\begin{aligned}
Y= & b_{0}+b_{1} X_{1}+b_{2} X_{2}+b_{3} X_{3}+b_{11}\left(X_{1} X_{1}\right)+b_{22}\left(X_{2} X_{2}\right) \\
& +b_{33}\left(X_{3} X_{3}\right)+b_{12}\left(X_{1} X_{2}\right)+b_{13}\left(X_{1} X_{3}\right)+b_{23}\left(X_{2} X_{3}\right)
\end{aligned}
$$

where, $\mathrm{Y}$ is the predicted response, $b_{0}$ a constant coefficient, bi a linear coefficient, bii a quadratic coefficient, bij an interaction coefficient, $X_{1}$ coded variables of concentration of $\mathrm{AgNO}_{3}$ and adsorption temperature. $X_{2}$ coded variables of Impregnation temperature and $\mathrm{pH}$ and $X_{3}$ coded variables of impregnation time andratio atrazine $/ \mathrm{CaCl}_{2}$ ) of the impregnated activated carbon variables and adsorption of atrazine variables respectively. The experimental data were analysed using software named NEMROD (New Efficient Methodology of research using optimal design); for regression analysis, to fit the equations developed and also to evaluate the statistical significance of the equations obtains [9].

\subsection{Adsorption Experiment}

The batch experiments for the adsorption studies were carried out at room temperature in conical flask of $150 \mathrm{~mL}$. For each run, $10 \mathrm{mg}$ of the adsorbent was introduced into the flask containing $100 \mathrm{~mL}$ of the atrazine solution at initial concentrations of $20 \mathrm{mg} / \mathrm{L}$. The shaker was set at a desired temperature $\left(15^{\circ} \mathrm{C}\right.$ $\left.35^{\circ} \mathrm{C}\right)$ at a speed of $250 \mathrm{rpm}$ and the solution at a desired $\mathrm{pH}(3.4-8.6)$ and at a desired ratio atrazine $/ \mathrm{CaCl}_{2}(0.37$ - 1.83). After reaching the equilibrium, $\mathrm{AC}-\mathrm{Ag}$ were separated from the aqueous solution using filtration method with $0.45 \mu \mathrm{m}$ what man cellulose nitrate menbrane. Then, the analysis of the residual solution was performed by UV-visible spectrophotometer Secomam at $225 \mathrm{~nm}$. The quantities adsorbed at equilibrium; $Q e\left(\mathrm{mg}^{-1} \mathrm{~g}^{-1}\right)$ were calculated according to:

$$
Q=\left(C_{0}-C_{t}\right) V / m
$$

where, $C_{0}$ and $C_{e}(\mathrm{mg} / \mathrm{L})$ are the initial and equilibrium concentrations of atrazine in solution, respectively, $V(\mathrm{~L})$ is the total volume of the solution, and $m(\mathrm{~g})$ is the adsorbent mass.

\section{Results and Discussion}

\subsection{Development of Regression Models Equation}

The examination of the given results in Table 1 showed that, the adsorption capacities of atrazine $\left(\mathrm{Y}_{1}\right)$ ranged from 270 to $384.62 \mathrm{mg} / \mathrm{g}$. The adsorption capacity of atrazine has a high value for $\left[\mathrm{AgNO}_{3}\right]=0.063 \mathrm{M}$; at $223^{\circ} \mathrm{C}$ and at $1.3 \mathrm{~h}$ (experiment 8), whereas, the lowest value was obtained at the same $\left[\mathrm{AgNO}_{3}\right]=$ $0.063 \mathrm{M}$ but now at $257^{\circ} \mathrm{C}$ and $3.7 \mathrm{~h}$ (experiment 11).

Nevertheless, for the removal of atrazine in function of medium conditions, Table 3 showed the capacity of the carbon samples to adsorb atrazine which varies between 157.69 and $209.45 \mathrm{mg} / \mathrm{g}$.

\subsection{The Effect of Factors on the Atrazine Adsorption Capacities $\left(\mathrm{Y}_{1}\right)$}

The polynomial model equation in terms of coded factors is given as: 
Table 3. Experimental design Matrix: operating conditions and the corresponding experimental response for the adsorption of atrazine in function of medium conditions.

\begin{tabular}{|c|c|c|c|c|}
\hline $\mathrm{N}^{\circ} \operatorname{Exp}$ & Temperature ${ }^{\circ} \mathrm{C}$ & $\mathrm{pH}$ & Ratio Atrazine- $\mathrm{CaCl}_{2}$ & $\mathrm{Y}_{2} \mathrm{mg} / \mathrm{g}$ \\
\hline 1 & 35.0 & 6.0 & 1.1 & 176.51 \\
\hline 2 & 15.0 & 6.0 & 1.1 & 169.64 \\
\hline 3 & 30.0 & 8.6 & 1.1 & 157.69 \\
\hline 4 & 20.0 & 3.4 & 1.1 & 179.25 \\
\hline 5 & 30.0 & 3.4 & 1.1 & 162.50 \\
\hline 6 & 20.0 & 8.6 & 1.1 & 176.00 \\
\hline 7 & 30.0 & 6.9 & 1.83 & 179.9 \\
\hline 8 & 20.0 & 5.1 & 0.37 & 180.52 \\
\hline 9 & 30.0 & 5.1 & 0.37 & 183.82 \\
\hline 10 & 25.0 & 7.7 & 0.37 & 209.45 \\
\hline 11 & 20.0 & 6.9 & 1.83 & 195.53 \\
\hline 12 & 25.0 & 4.3 & 1.83 & 196.02 \\
\hline 13 & 25.0 & 6.0 & 1.1 & 193.88 \\
\hline 14 & 25.0 & 6.0 & 1.1 & 195.23 \\
\hline 15 & 25.0 & 6.0 & 1.1 & 176.32 \\
\hline 16 & 25.0 & 6.0 & 1.1 & 195.5 \\
\hline 17 & 25.0 & 6.0 & 1.1 & 187.14 \\
\hline
\end{tabular}

$$
\begin{aligned}
Y_{1}= & 297.452-8.904 X_{1}-28.168 X_{2}-42.360 X_{3}+53.533 X_{1}^{2}+4.883 X_{2}^{2} \\
& +31.497 X_{3}^{2}+11.497 X_{1} X_{2}+32.139 X_{1} X_{3}-67.073 X_{2} X_{3}
\end{aligned}
$$

The quality of the developed model was evaluated based on the correlation coefficient, $R^{2}$ and the adjusted $R^{2}$ indicating that the variability in the response could be explained by the mathematical model [10]. In this case, the correlation between the theoretical and experimental responses, calculated by the model is satisfactory: $R^{2}=0.984$ and adjusted $R^{2}=0.964$. In the case of response $Y_{1}$, the positive sign in front of the terms indicates synergistic effect whereas negative sign indicates antagonistic effect [11] [12]. Table 2 shows the analysis of variance (ANOVA) of response $Y_{1}$, it is clear that, the impregnation time $\left(b_{3}=\right.$ $-42.360)$ and carbonization temperature $\left(b_{2}=-28.168\right)$ have a significant effect for the adsorption of atrazine. But the concentration of $\mathrm{AgNO}_{3}$ has no significant effect on this response. The quadratic term of concentration of silver $\left(b_{11}=\right.$ 53.533), impregnation time $\left(b_{33}=31.497\right)$ have a significant effect on the response and the interaction between impregnation temperature and time $\left(b_{23}=\right.$ -67.073) imposing the most effect.

Figure 1(a) and Figure 1(b) shows the two and three dimensional response surface which were constructed to present the most important factors on the atrazine removal by $\mathrm{AC}-\mathrm{Ag}$

The Figures shows that, atrazine adsorption increases when the $\left[\mathrm{AgNO}_{3}\right]$ in- 


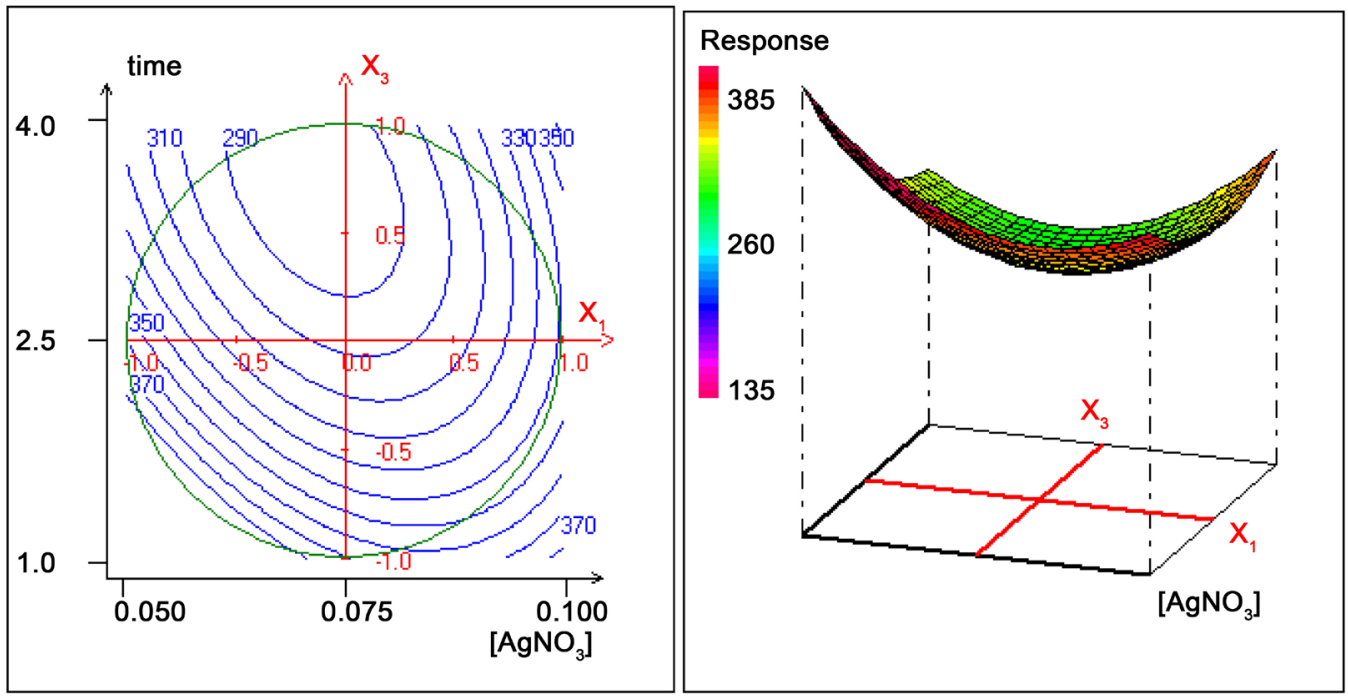

(a)

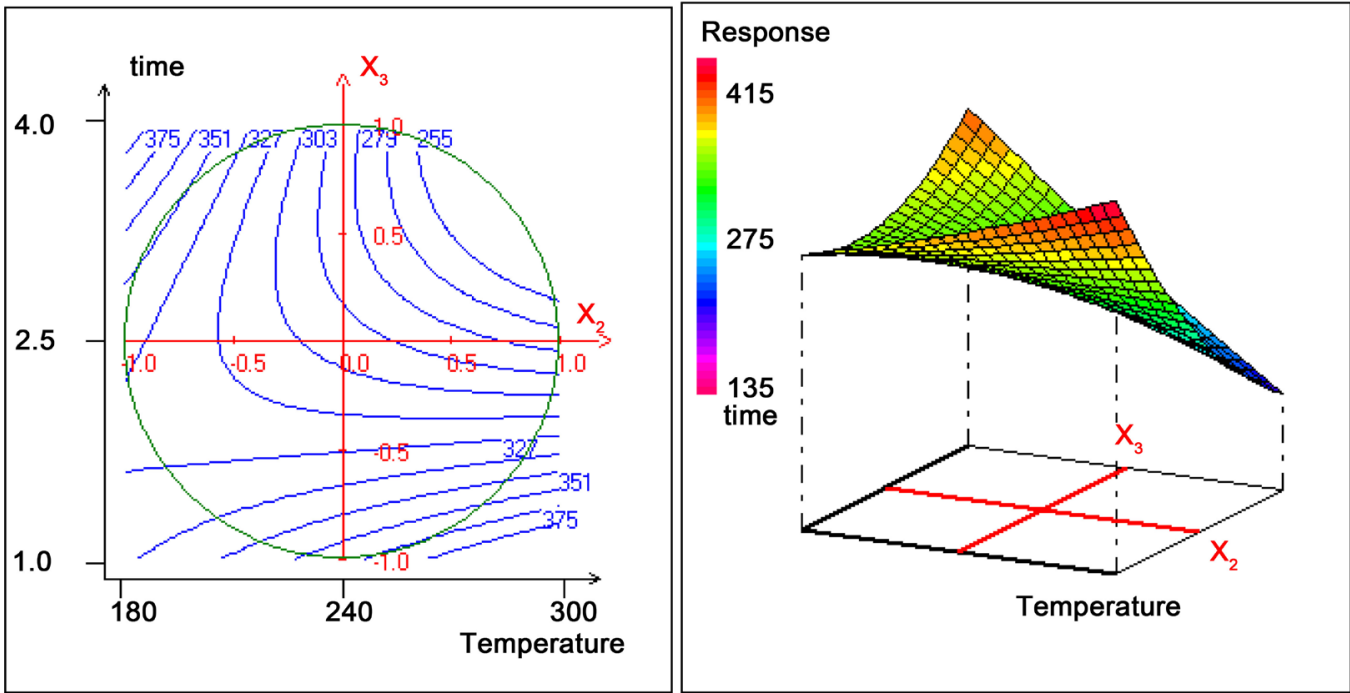

(b)

Figure 1. (a) Variation of the Atrazine adsorption $\left(\mathrm{Y}_{1} \mathrm{mg} / \mathrm{g}\right)$ in the plan Time (h)- $\left[\mathrm{AgNO}_{3}\right](\mathrm{mol} / \mathrm{L})$; (b) Variation of the Atrazine adsorption $\left(\mathrm{Y}_{1}\right)$ in the plan Temperature $\left({ }^{\circ} \mathrm{C}\right)$-Time $(\mathrm{h})$.

crease. It is found that, atrazine exists almost exclusively as neutral molecules, and the weak forces such as van der waals forces, hydrogen bonds and hydrophobic interaction would involve in the reciprocity of atrazine with activated carbon [3]. Similar results have been reported by Emily et al. [13]; Park et al. [14]; Quing-Hui and Hong-Xiao [15].

From Figure 1(b), at low temperature $\left(\mathrm{T}=180^{\circ} \mathrm{C}\right), \mathrm{Y}_{1}$ increase when time increases from $1 \mathrm{~h}$ to $4 \mathrm{~h}$ in contrast at high temperature $\left(300^{\circ} \mathrm{C}\right), \mathrm{Y}_{1}$ decrease when time increases. However, at low temperature, the iron was not crystallized in the activated carbon surface, which gave free active sites on the adsorbent that were favorable for the adsorption of atrazine. The second observation indicates that, the uptake of atrazine on activated carbon was an exothermic process [16]. Nevertheless, Urena-Amate et al. [17] explained this phenomenon by the fact that at high temperature, the formation of the unions between the activated car- 
bon surface and the atrazine molecules will be diminished. Probably due as the content of iron in the composite increases because the surface area decrease caused by the presence of a high quantity of iron oxide in the activated carbon/Iron oxide occupying the active sites avoiding the contact of atrazine molecules to adsorption sites on the carbon surface [2].

\subsection{Effect of Medium Condition on Removal of Atrazine $\left(\mathrm{Y}_{2}\right)$}

This response is described by the following equation:

$$
\begin{aligned}
Y_{2}= & 191.54+2.556 X_{1}+8.352 X_{2}-4.040 X_{3}-18.472 X_{1}^{2}-14.066 X_{2}^{2} \\
& +3.144 X_{3}^{2}+16.468 X_{1} X_{2}-7.948 X_{1} X_{3}-29.624 X_{2} X_{3}
\end{aligned}
$$

With a significant correlation coefficient $\left(R^{2}=0.929\right.$ and $R^{2}$ adjusted $\left.=0.893\right)$. The coefficients estimated from the results are displayed in Table 4 . The analysis of the different effects showed a significant effect of $\mathrm{pH}$ for the removal of atrazine. The interaction $b_{13}$ and $b_{23}$ have a significant effect on the capacity of atrazine adsorption (Y1).

This Figures 2-4 showed the variation of atrazine adsorption as a function of different factors. Figure 2 shows the combined effect of $\mathrm{pH}$ and temperature on adsorption of atrazine. It is evident from the Figure 2 that the adsorption capacity of atrazine increases when the temperature and $\mathrm{pH}$ increases. This result agrees with recent studies which reported that removal efficiency of micropollutants is generally lower at low temperature [4]. But this response decreases when rAyraz/ $/ \mathrm{CaCl}_{2}$ and temperature increases (Figure 3), it may be due, to an increase in the atrazine solubility in this step, implying a decrease of hydrophobics interactions [18]. The net effect of inorganic salts on atrazine sorption can be explain by two opposite factors: as increase in the solution, ionic strength can partially dissociate hydroxyls groups on adsorbent, disfavoring the H-bond with atrazine. Moreover, the addition of inorganic salts reduces the double layers thickness and strengthens the hydrophobic interactions that facilitate atrazine sorption [19]. Therefore, the increase in temperature caused a decrease in ad-

Table 4. Estimated values of coefficients for $\mathrm{Y}_{2}$.

\begin{tabular}{cccccc}
\hline Name & Coefficient & F.Inflation & Standard déviation & t.exp & Signif.\% \\
\hline $\mathrm{b}_{0}$ & 191.547 & & 1.282 & 149.40 & $<0.01^{\star * *}$ \\
$\mathrm{~b}_{1}$ & 2.556 & 1.14 & 1.441 & 1.77 & 9.0 \\
$\mathrm{~b}_{2}$ & 8.352 & 1.31 & 1.797 & 4.65 & $0.0234^{\star * *}$ \\
$\mathrm{~b}_{3}$ & -4.040 & 1.04 & 1.369 & -2.95 & $0.834^{\star *}$ \\
$\mathrm{~b}_{11}$ & -18.472 & 1.10 & 2.221 & -8.32 & $<0.01^{\star * *}$ \\
$\mathrm{~b}_{22}$ & -14.066 & 1.79 & 3.306 & -4.25 & $0.0529^{\star * *}$ \\
$\mathrm{~b}_{33}$ & 3.144 & 1.13 & 2.234 & 1.41 & 17.3 \\
$\mathrm{~b}_{12}$ & 16.468 & 2.12 & 5.174 & 3.18 & $0.510^{\star *}$ \\
$\mathrm{~b}_{13}$ & -7.948 & 1.34 & 3.635 & -2.19 & $4.03^{*}$ \\
$\mathrm{~b}_{23}$ & -29.624 & 1.18 & 3.744 & -7.91 & $<0.01^{\star * *}$ \\
\hline
\end{tabular}




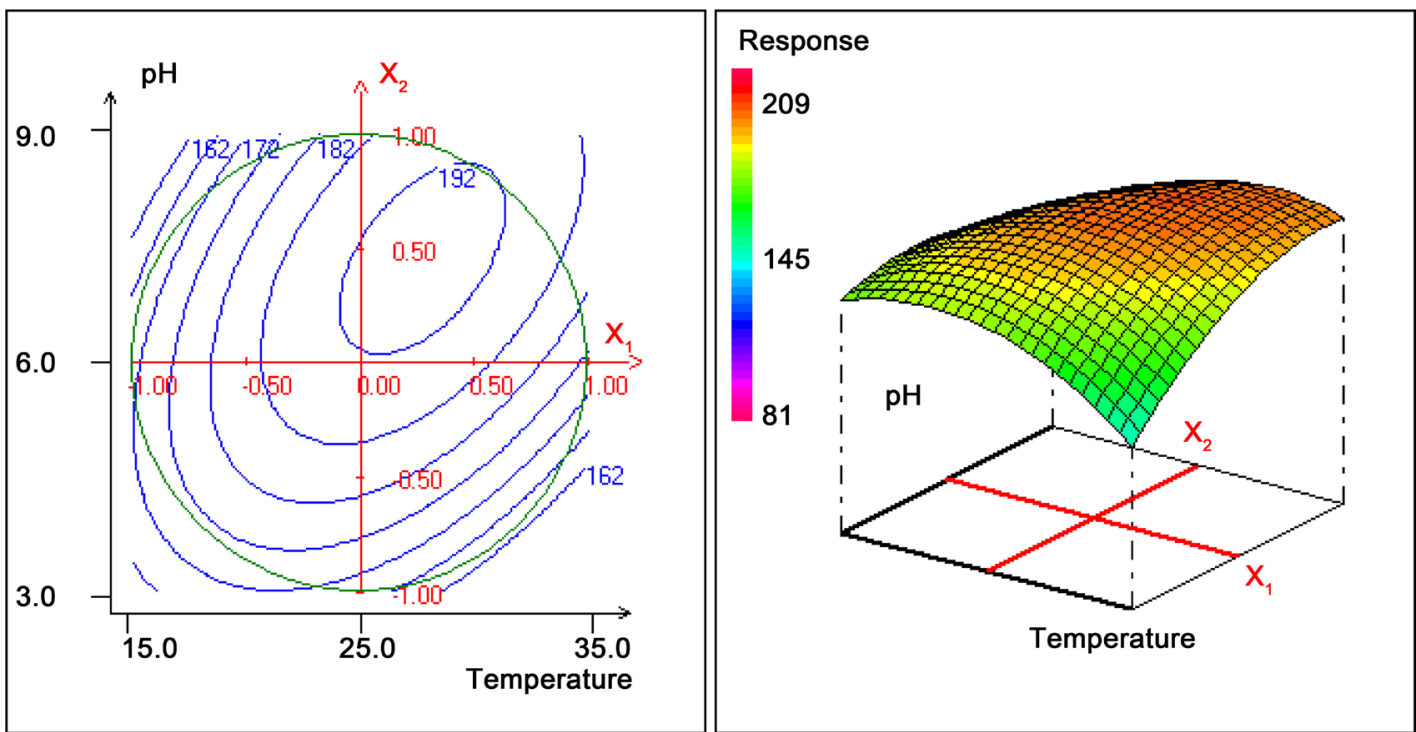

Figure 2. Variation of atrazine adsorption capacity $\left(\mathrm{Y}_{2} ; \mathrm{mg} / \mathrm{g}\right)$, as a function of $\mathrm{pH}\left(\mathrm{X}_{2}\right)$ and Temperature $\left(\mathrm{X}_{1}\right)$.

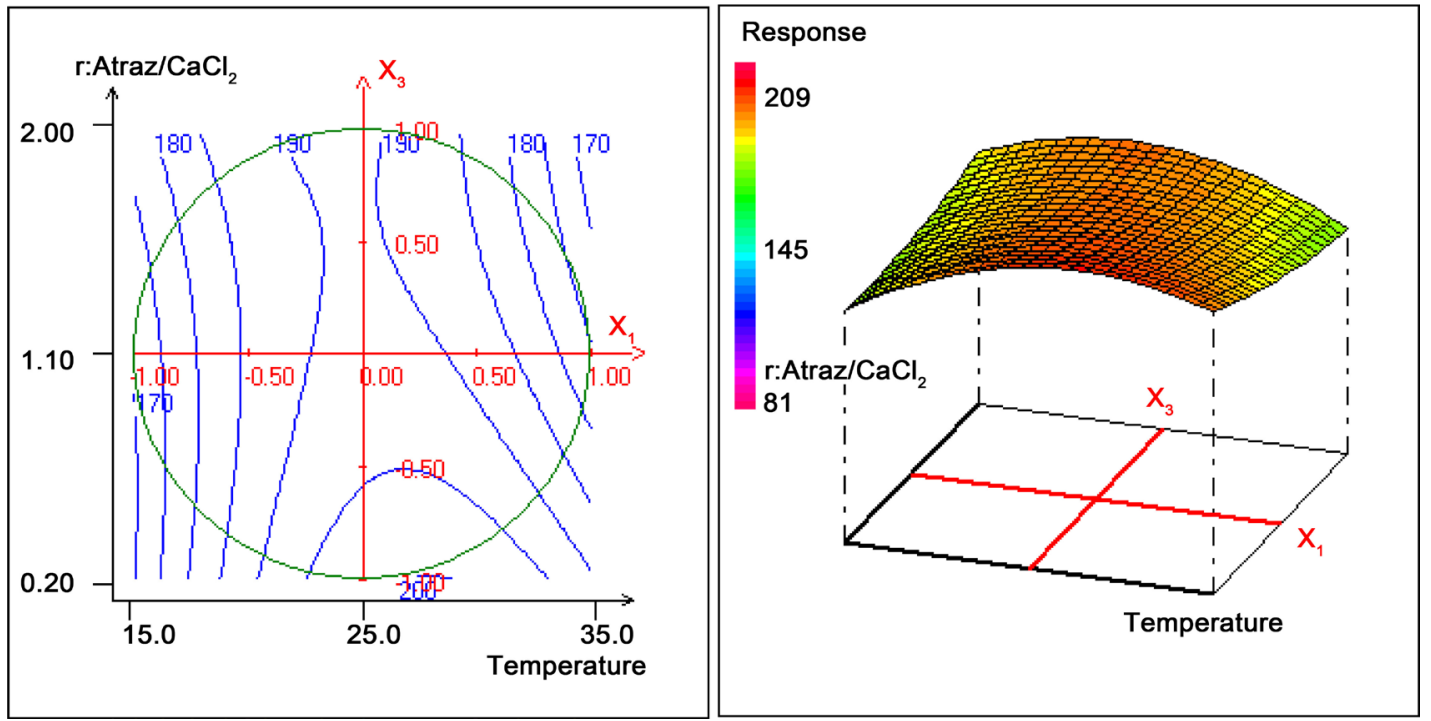

Figure 3. Variation of atrazine adsorption capacity $\left(\mathrm{Y}_{2} ; \mathrm{mg} / \mathrm{g}\right)$, as a function of $\mathrm{r} \mathrm{Atraz} / \mathrm{CaCl}_{2}\left(\mathrm{X}_{3}\right)$ and Temperature $\left(\mathrm{X}_{1}\right)$.

sorbed atrazine, indicating that, the process was exothermic [17]. Nevertheless, Figure 4 shows the interaction between $\mathrm{pH}$ and $\mathrm{r}\left(\mathrm{Atrz} / \mathrm{CaCl}_{2}\right)$. Indeed, at low $\mathrm{pH}$ the increase of $\mathrm{r}\left(\operatorname{atraz} / \mathrm{CaCl}_{2}\right)$ increase $\mathrm{Y}_{2}$. In contrast at high $\mathrm{pH}$, the increase of $\mathrm{r}\left(\mathrm{atraz} / \mathrm{CaCl}_{2}\right)$ decreases $\mathrm{Y}_{2}$. The observed ionic strength effects on atrazine adsorption reflect a cooperative effect both, $\mathrm{Ca}^{2+}$ and $\mathrm{Cl}^{-}$. At low $\mathrm{pH}$, positively charged surface would favor ion pair formation between $\mathrm{Cl}^{-}$and $\mathrm{AC} / \mathrm{Ag}$. But, atrazine maintains its non-ionized form and is adsorbed onto $\mathrm{AC} / \mathrm{Ag}$. The increase of $\mathrm{Y}_{2}$ when of $\mathrm{r}\left(\mathrm{atraz} / \mathrm{CaCl}_{2}\right)$ increases at low $\mathrm{pH}$ is probably due to the best affinity of atrazine onto $\mathrm{AC} / \mathrm{Ag}$ surface and we can conclude that $\mathrm{Cl}^{-}$has a weak binding with $\mathrm{AC} / \mathrm{Ag}$. For this reason, Jianghua et al., said that, acidic condition is more favorable to this adsorption process [20]. However, 


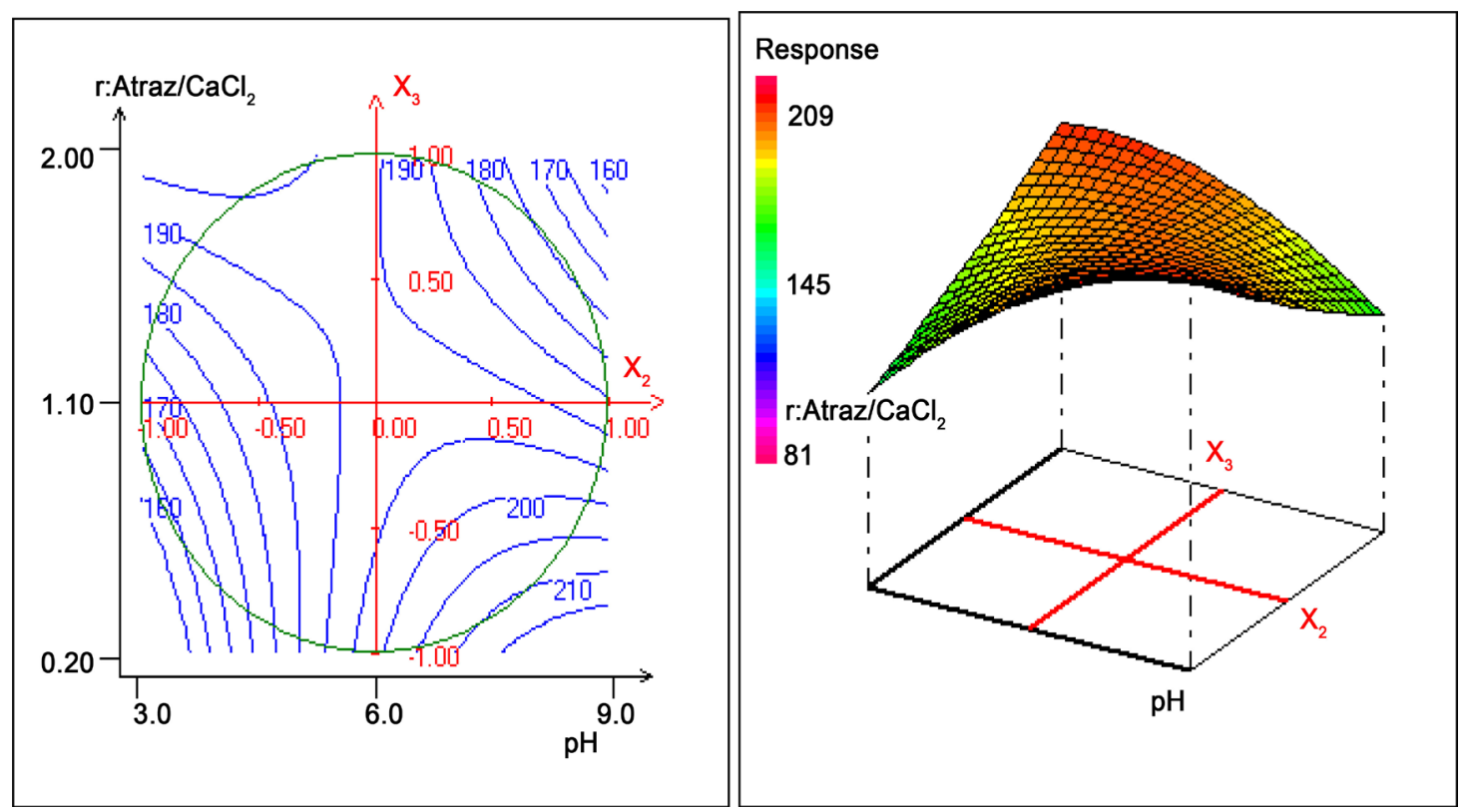

Figure 4. Variation adsorption capacity of atrazine $\left(\mathrm{Y}_{2} ; \mathrm{mg} / \mathrm{g}\right)$, as a function of $\mathrm{pH}$ and $\mathrm{rAtraz} / \mathrm{CaCl}_{2}$.

at high $\mathrm{pH}$, atrazine can be converted to a negative charge from the protonated base in basic solution. The number of negatively charged adsorbent sites increased at $\mathrm{pH}>6.93$, limiting the adsorption of atrazine. But the increase ofr (atraz $/ \mathrm{CaCl}_{2}$ ) at high $\mathrm{pH}$ enhances ion pair formation between $\mathrm{Ca}^{2+}$ and $\mathrm{AC} / \mathrm{Ag}$ who is charge negatively. Consequently, electric repulsion between the negatively charged $\mathrm{AC} / \mathrm{Ag}$ surface and atrazine might have occurred at high $\mathrm{pH}$ [21].

\subsection{Process Optimization}

The preparation of composite $\mathrm{AC} / \mathrm{Ag}$ was done under the experimental conditions given in Table 1 and the experimental conditions of removal of atrazine as a function of medium condition given in Table 3. The optimum condition for activated carbon composite were obtained using preparation conditions of: 0.063 $\mathrm{mol} / \mathrm{L}$ concentration of silver, $223^{\circ} \mathrm{C}$ impregnation temperature and 1.3 -hour impregnation time which conducted to $Y_{1}$ equal at $384 \mathrm{mg} / \mathrm{g}$. Whereas, the optimum adsorption of atrazine under effect of medium conditions were obtained at: $25^{\circ} \mathrm{C}, \mathrm{pH} 7.7$ and $0.37 \mathrm{rAtraz} / \mathrm{CaCl}_{2}$ for $\mathrm{Y}_{2}$ of $209 \mathrm{mg} / \mathrm{g}$. It is clear that the medium conditions have a high effect on the efficiency of atrazine at $20 \mathrm{mg} / \mathrm{L}$ of concentration. From the literature, Llado et al, used a commercial activated carbon Filtrasorb 400 for the adsorption of atrazine and found that the maximum adsorption capacity was $212 \mathrm{mg} / \mathrm{g}$ at $40 \mathrm{mg} / \mathrm{L}$ concentration of atrazine [6]. Thus, the composite AC/Ag prepared in this work is suitable to be used for the removal of atrazine in aqueous solution.

\subsection{Characterization of Activated Carbon Prepared under Optimum Condition}

Figure 5 shows the EDX spectrum of the defined area of AC-Ag. The characteristic peaks of $\mathrm{Ag}$ and Carbon were clearly observed, indicating the existence of 


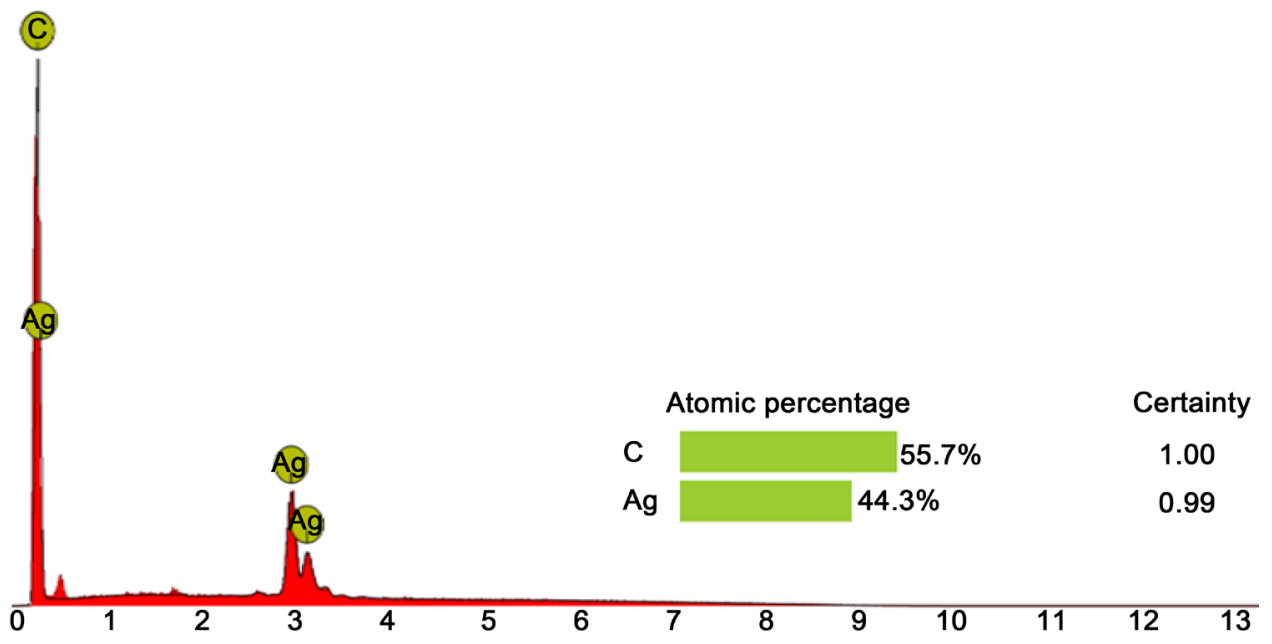

209,610 courts in 270 seconds

Figure 5. EDX spectrum of AC-Ag.

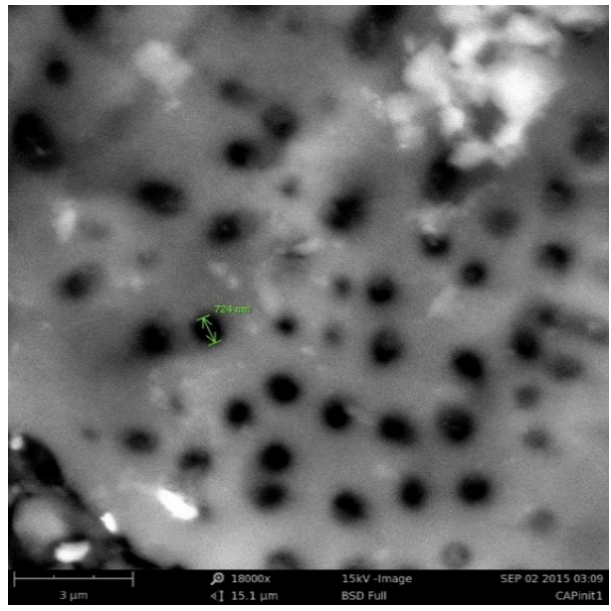

(a)

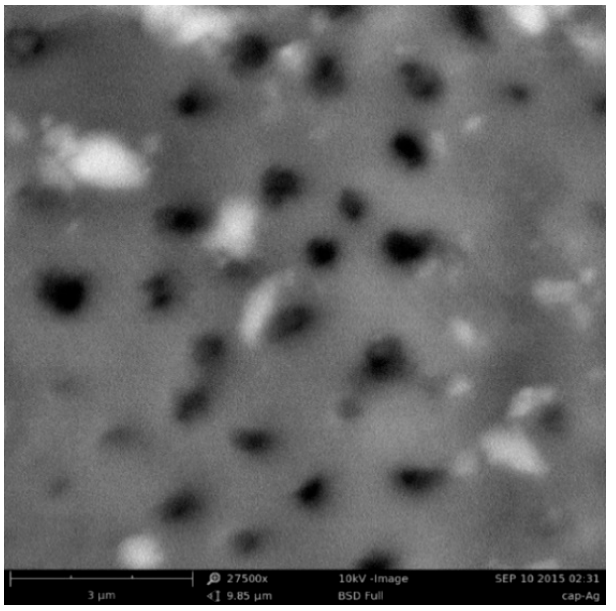

(b)

Figure 6. (a) The SEM image of AC; (b) The SEM image of AC-Ag.

$\mathrm{Ag}$ at $44.3 \%$ and Carbon at $55.7 \%$. The SEM images of $\mathrm{AC}$ and $\mathrm{AC}-\mathrm{Ag}$ are shown in Figure 6. We can observe many orderly and developed pores due to the effect of the steam activation produced on the oil palm shell in a first time demonstrated by homogenous circle shapes with same sizes of uniformly distributed pores (Figure 6(a)). But, after impregnation with silver, we can observe that, $\mathrm{Ag}$ particles were covered on the surface of $\mathrm{AC}$ hindering some of the pores (Figure 6(b)).

The Fourier Transform Infrared (FTIR) spectra of AC and AC-Ag (Figure 7) indicates the formation of large number of hydroxyl or phenolic hydroxyl groups on the surface of AC at 3411 and $3451 \mathrm{~cm}^{-1}$ [20]. The O-H stretching vibration $\left(3408-3452 \mathrm{~cm}^{-1}\right)$ and $\mathrm{C}-\mathrm{OH}$ stretching vibration $\left(999-1027 \mathrm{~cm}^{-1}\right)$ were more obvious and broader in all samples. The three peaks located at about 1654 and $1575 \mathrm{~cm}^{-1}$ could be assigned to $\mathrm{C}=\mathrm{O}$ vibration and in-plane $\mathrm{C}=\mathrm{C}$ stretching vibration of aromatic ring, respectively for $\mathrm{AC}-\mathrm{Ag}$ and $\mathrm{AC}$, which supported the concept of aromatization of the activated carbon. The bands in 
the range $1000-1500 \mathrm{~cm}^{-1}$, which include the $\mathrm{C}-\mathrm{OH}$ stretching and $\mathrm{OH}$ bending vibrations, imply the existence of large numbers of residual hydroxy groups $(\mathrm{OH})$ and carboxylate groups $(\mathrm{COOH})[22]$. The $\mathrm{OH}$ and $\mathrm{COOH}$ can react with metal ions to form metal nanoparticles [23]. It can be concluded that the surface functional groups changed largely. Moreover, aromatic $\mathrm{C}=\mathrm{C}$ stretching (skeletal ring vibration) at about $1654 \mathrm{~cm}^{-1}$ increased sharply.

Figure 8, show that the $\mathrm{pH}_{\mathrm{Pzc}}=6.93$; In this case, the surface charge of $\mathrm{AC} / \mathrm{Ag}$

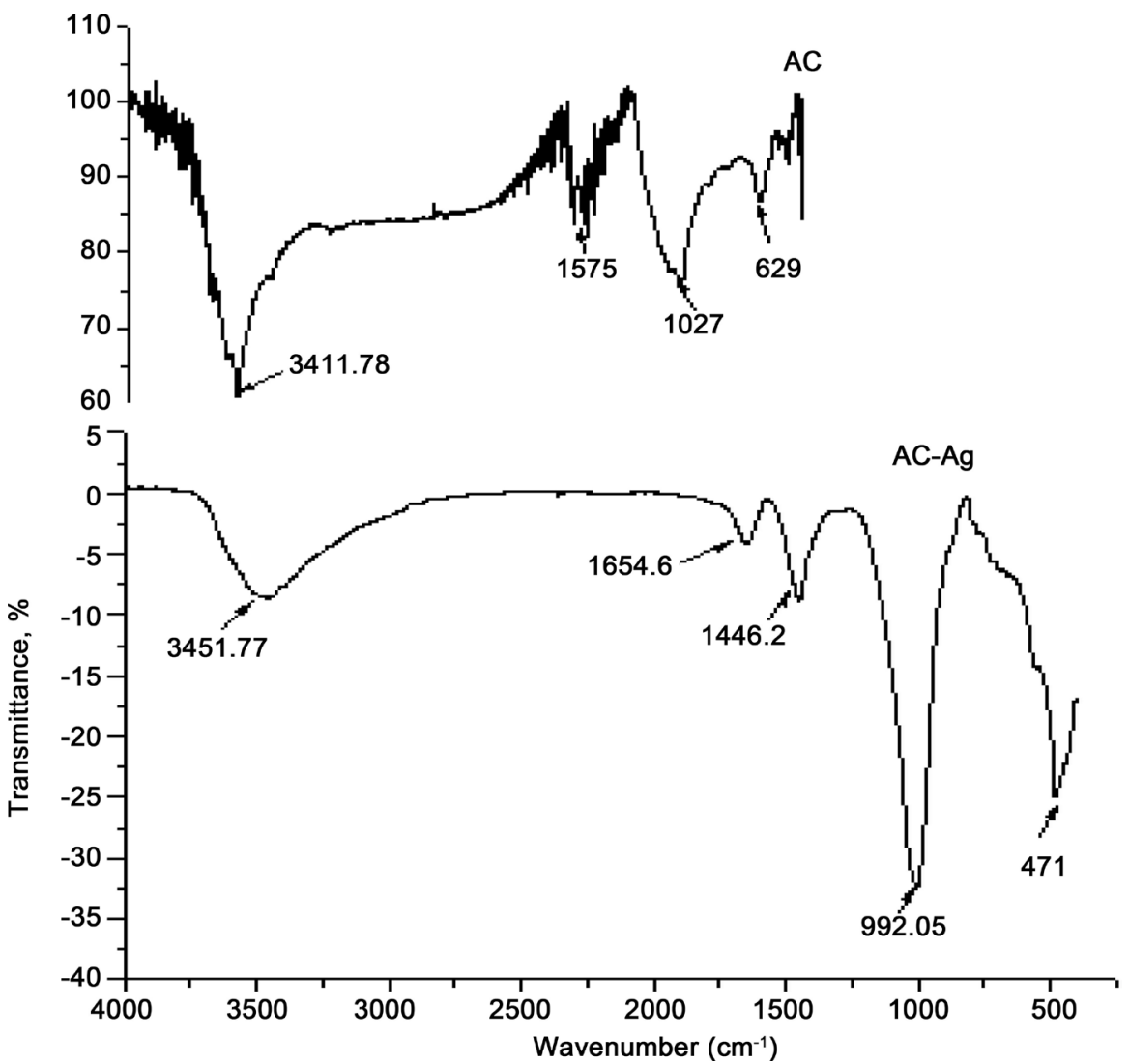

Figure 7. FTIR spectra of AC and AC-Ag.

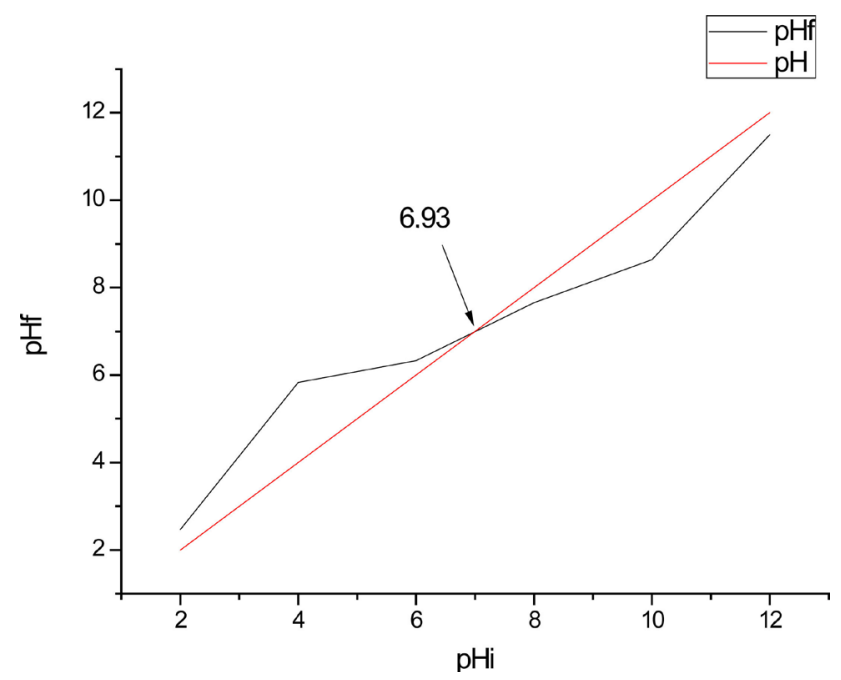

Figure 8. $\mathrm{pH}_{\mathrm{PZC}}$ of composite AC-Ag. 
was positive when $\mathrm{pH}$ is below $\mathrm{pH}_{\mathrm{Pzc}}$ and negative when $\mathrm{pH}$ is above $\mathrm{pH}_{\mathrm{Pzc}}$.

\section{Conclusion}

The composite AC-Ag has been prepared for adsorption of atrazine. The impregnation condition of AC-Ag and the removal of atrazine have been optimized using Response Surface Methodology (Doehlert design). The second polynomial equation has been found to fit most satisfactorily the model predicted according to the correlation coefficients obtained. The obtained adsorption capacities were $384 \mathrm{mg} / \mathrm{g}$ for optimum condition of impregnation and $209 \mathrm{mg} / \mathrm{g}$ for a medium condition for adsorption. It is clear that the medium condition has the less effect on the adsorption of atrazine. Finally, it can be concluded that AC-Ag has an excellent potential of adsorption of atrazine. Therefore, it can be efficiently used for treatment of industrial effluent containing these pollutants.

\section{Acknowledgements}

Dr. BEAS of the University of Technology of Johannesburg is highly acknowledged for his assistance in analysis and interpretation, remarks and suggestions in the write up of this paper. The authors thank the Applied Organic Chemistry Laboratory of the Chemistry Department, Faculty of Science Semlalia, Cadi Ayyad University of Morocco, for the materials and logistics support. And finally thank all the members of the Research Unit "Adsorption and Surface" of the Applied Physical and Analytical Chemistry Laboratory of the University of Yaoundé I.

\section{References}

[1] Zhang, C., Yan, J., Zhang, C. and Yang, Z. (2012) Enhanced Adsorption of Atrazine from Aqueuous Solution by Molecularly Imprinted $\mathrm{TiO}_{2}$ Film. Solid State Sciences, 14, 777-781.

[2] Castro, C.S., Guerreiro, M.C., Goncalves, M., Oliveira, L.C.A. and Anastacio, A.S. (2009) Activated Carbon/Iron Oxide Composites for the Removal of Atrazine from Aqueous Medium. Journal of Hazardous Materials, 164, 609-614.

[3] Tang, W.W., Zeng, G.M., Gong, J.L., Liu, Y., Wang, X.-Y., Liu, Y.-Y., Liu, Z.F., Chen, L., Zhang, X.-R. and Tu, D.-Z. (2012) Simultaneous Adsorption of Atrazine and $\mathrm{Cu}(\mathrm{II})$ from Wastewater by Magnetic Multi-Walled Carbon Nanotube. Chemical Engineering Journal, 211-212, 470-478.

[4] Nam, S.W., Choi, D.J., Kim, S.K., Her, N. and Zoh, K.D. (2014) Adsorption Characteristics of Selected Hydrophilic and Hydrophobic Micropollutants in Water Using Activated Carbon. Journal of Hazardous Materials, 270, 144-152.

[5] Al Bahri, M., Calvo, L., Lemus, J., Gilarranz, M.A., Palomar, J. and Rodriguez, J.J. (2012) Mechanistic Understanding of the Behavior of Diuron in the Adsorption from Water onto Activated Carbon. Chemical Engineering Journal, 198-199, $346-$ 354

[6] Llado, J., Lao-Luque, C., Ruiz, B., Fuente, E., Solé-Sardans, M. and Dorado, A.D. (2015) Role of Activated Carbon Properties in Atrazine and Paracetamol Adsorption Equilibrium and Kinetics. Process Safety and Environment Protection, 95 51-59. https://doi.org/10.1016/j.psep.2015.02.013 
[7] Tan, I.A., Ahmad, AL. and Hamed, B.H. (2008) Preparation of Activated Carbon from Coconut Husk: Optimization Study on Removal of 2,4,6-Trichlorophenol Using Response Surface Methodology. Journal of Hazardous Materials, 153, 709-717.

[8] Hesas, R.H., Arami-Niyaa, A., Dauda, W. and Sahu, J.N. (2013) Preparation of Granular Activated Carbon from Oil Palm Shell by Microwave-Induced Chemical Activation: Optimisation Using Surface Response Methodology. Chemical Engineering Research and Design, 91, 2447-2456.

https://doi.org/10.1016/j.cherd.2013.06.004

[9] Ennaciri, K., Baçaoui, A., Sergent, M. and Yaacoubi, A. (2014) Application of Fractional Factorial and Doehlert Designs for Optimizing the Preparation of Activated Carbons from Argan Shells. Chemometrics and Intelligent Laboratory Systems, 139, 48-57.

[10] Sumathi, S., Bathia, S., Lee, K.T. and Mohammed, A.R. (2009) Optimizations of Microporous Palm Shell Activated Carbon Production for Flue Gas Desulphurization: Experimental and Statistical Studies. Bioresource Technology, 100, 1614-1621.

[11] Hameed, B.H., Tan, I.A.W. and Hamad, A. (2009) Preparation of Oil Palm Empty Fruit Bunch-Based Activated Carbon for Removal of 2,4,6-Trichlorophenol: Optimization Using Response Surface Methodology. Journal of Hazardous Materials, 164, 1316-1324.

[12] Kouotou, D., Ngomo Manga, H., Baçaoui, A., Yaacoubi, A. and KetchaMbadcam, J. (2013) Physicochemical Activation of Oil Palm Shells Using Response Surface Methodology: Optimization of Activated Carbon Preparation. International Journal of Current Research, 5, 431-438.

[13] Grundgeiger, E., Lim, Y.H., Frost, R.L., Ayoko, G.A. and Xi, Y.F. (2015) Application of Organo-Beidellites for the Adsorption of Atrazine. Applied Clay Science, 105106, 252-258.

[14] Park, Y., Sun, Z., Ayoko, G.A. and Frost, R. (2014) Removal of Herbicides from Aqueous Solutions by Modified Forms of Montmorillonite. Journal of Colloid and Interface Science, 415, 127-132.

[15] Tao, Q.H. and Tang, H.X. (2004) Effect of Dye Compounds on the Adsorption of Atrazine by Natural Sediment. Chemosphere, 56, 31-38.

[16] Chingombe, P., Saha, B. and Wakema, R.J. (2006) Sorption of Atrazine on Conventional and Surface Modified Activated Carbon. Journal of Colloid and Interface Science, 304, 408-416.

[17] Urena-Amate, M.D., Socias-Viciana, M., Gonzalez-Pradas, E. and Saifi, M. (2005) Effects of Ionic Strength and Temperature on Adsorption of Atrazine by Heat Treated Kerolite. Chemosphere, 59, 69-74.

[18] Pastrana-Martinez, L.M., Lopez-Ramon, M.V. and Moreno-Castilla, C. (2009) Adsorption and Thermal Desorption of the Herbicide Fluroxypyr on Activated Carbon Fibers and Cloth at Different $\mathrm{pH}$ Values. Journal of Colloid and Interface Science, 331, 2-7.

[19] Zhang, W., Zheng, J., Zheng, P. and Qiu, R. (2015) Atrazine Immobilization on Sludge Derived Biochar and the Interactive Influence of Coexisting pb(II) or $\mathrm{Cr}(\mathrm{VI})$ Ions. Chemosphere, 134, 438-445.

[20] Qiu, J., Wang, G., Bao, Y., Zeng, DZ. and Chen, Y. (2015) Effect of Oxidative Modification of Coal Tar Pitch-Based Mesoporous Activated Carbon on the Adsorption of Benzothiophene and Dibenzothiophene. Fuel Process Technology, 129, 85-90.

[21] Salma, J.M., Njoku, V.O. and Hameed, B.H. (2011) Adsorption of Pesticides from Aqueous Solution onto Banana Stalk Activated Carbon. Chemical Engineering Journal, 174, 41-48. 
[22] Chen, Q. and Wu, Q. (2015) Preparation of Carbon Microspheres Decorated with Silver Nanoparticles and Their Ability to Remove Dyes from Aqueous Solution. Journal of Hazardous Materials, 283, 193-201.

[23] Song, X., Gunawan, P., Jiang, R., Leong, S.S.J., Wang, K. and Xu, R. (2011) Surface Activated Carbon Nanospheres for Fast Adsorption of Silver Ions from Aqueous Solutions. Journal of Hazardous Materials, 194, 162-168.

Submit or recommend next manuscript to SCIRP and we will provide best service for you:

Accepting pre-submission inquiries through Email, Facebook, LinkedIn, Twitter, etc. A wide selection of journals (inclusive of 9 subjects, more than 200 journals)

Providing 24-hour high-quality service

User-friendly online submission system

Fair and swift peer-review system

Efficient typesetting and proofreading procedure

Display of the result of downloads and visits, as well as the number of cited articles Maximum dissemination of your research work

Submit your manuscript at: http://papersubmission.scirp.org/

Or contact msa@scirp.org 